\title{
Dialéctica de la representación: una invitación teórico-metodológica*
}

Dialectic of representation: a theoretical-methodological invitation

\section{RESUMEN}

Es un lugar común en los estudios culturales y en las etnografías visuales contemporáneas relativizar al extremo la interpretación de las imágenes. Sin embargo, en toda relatividad existen constantes: elementos que superan la particularidad de la interpretación y que al identificarlos se podrá discutir de un modo más efectivo y enriquecedor alrededor de lo que llamamos imágenes. Esta es la premisa de este texto, en el cual se espera delinear un conjunto de estas constantes en el trabajo con lo que llamamos de un modo ambiguo imágenes y representaciones. En esta medida, se espera contribuir con la reducción de esta ambigüedad aportando a estos conceptos trasfondos interactivos y políticos que le dan contenido y forma a los procesos de percepción y de creación humanas, lo cual supera ampliamente los ámbitos de lo visual, tratando de contribuir un poco con discusiones de la semántica y la semiótica sin pretender ser parte de estas tradiciones, sino más bien invitando a pensar en un lenguaje común para los etnógrafos interesados en todo tipo de imágenes.

Palabras clave: representación, imagen, medio, metodología, interpretación.
Miguel Ángel

Rivera Fellner

Universidad de Caldas,

Manizales, Colombia.

\miguel.rivera@ucaldas.edu.co

(1) ORCID: 0000-0002-5911-8455

si Google Scholar

*Una primera versión de este texto fue expuesta como ponencia en el II Congreso Latinoamericano y Caribeño de Ciencias Sociales realizado en Quito, del 26 al 28 de agosto de 2015. 


\begin{abstract}
It is commonplace in cultural studies and contemporary visual ethnographies to extremely relativize the interpretation of images. However, in all relativity there are constants: elements that go beyond the particularity of interpretation and that by identifying them allow a more effective and enriching discussion on what we call images. This is the premise of this text, which aims to delineate a set of these constants in the work related to what we ambiguously call images and representations. This text purports to contribute to the reduction of this ambiguity by giving interactive and political backgrounds to these concepts, in a way that provides content and form to the processes of human perception and creation. This, far exceeds the fields of the visual, trying to partially contribute with discussions of semantics and semiotics without claiming to be part of these lines of inquiry, but rather inviting to think of a common language for ethnographers.
\end{abstract}

Keywords: representation, image, medium, methodology, interpretation.

\title{
Imágenes y sistemas de representación y significación
}

ste texto tiene como intención general tratar de otorgar un
punto de partida teórico que permita posibilidades prácticas
en términos metodológicos. Es decir, a partir de la aceptación de ciertos elementos teóricos de los últimos 30 años, se espera inspirar procedimientos y técnicas para la investigación alrededor de lo que llamamos, de un modo general, medios, imágenes y representaciones. En esta medida, este texto no espera ser una guía metodológica en sí misma sino en un primer conjunto de discusiones teóricas como parte de una eventual reflexión metodológica para cualquier interesado en estos temas.

Para ello, se debe comenzar reconociendo que la labor interpretativa alrededor de cualquier imagen nunca es infalible ni plena, por el contrario, es siempre parcial e implica una pérdida importante de cierto tipo de información en beneficio o relieve de otra. Esta premisa justificaría la siguiente pregunta: ¿qué se escapa o se desvanece en el acto de intermediación y traducción que viene a ser una representación y qué consecuencias trae esta pérdida? 
Este no es el espacio para evaluar la tradición escolástica de la semiología y la semiótica, sino más bien reconocer en algunos autores (cuasi)contemporáneos un punto de partida teórico para la acción investigativa. No son los únicos ni los más recientes, pero los considero los más cercanos a la mirada que espero esbozar. Para ello, tanto Hans Belting como Stuart Hall reconocerían que, así como se pierde algo, se gana algo, y esta pérdida/ganancia opera regularmente en la dirección de lo general a lo particular. Esto, entendiendo que la imagen como acto y como medio (Belting, 2002) es un vehículo que posibilita la concreción de la representación como proceso y como acción (en términos de Hall, 2001).

La noción de imagen que propone Belting con un tipo de análisis que llama antropológico, es complementaria con la idea de representación y de "significado social" que nos trata de compartir Hall. Por su parte, Belting (2002) propone separarse de las tradiciones semióticas y semiológicas clásicas que parecen haber caído en una especie de metafísica alrededor de los significados y hace un énfasis en el carácter medial o material que adquiere lo simbólico: "Solamente un enfoque antropológico puede devolver su lugar al ser humano, que se experimenta como medial e igualmente actúa de manera medial" (p. 18).

Esto quiere romper con las tendencias interpretativas de las imágenes en sí mismas y por sí mismas, como análisis los análisis trascendentalistas, olvidándose su carácter catalizador de las relaciones sociales, así como en la apropiación de la naturaleza y en la exploración de los mundos subjetivos. A través de la relación conceptual entre imagen, medio y cuerpo, Belting (2002) pretende mostrarnos una opción más amplia, al modo del Hecho Social Total de Marcel Mauss (1979), cómo nuestros cuerpos interactúan a través de imágenes a la vez que la generan, mostrando cómo somos los principales medios de tales imágenes a través de nuestros cuerpos; y que, a la vez, estas imágenes permiten trascender más allá de los cuerpos y las sociedades que las generaron:

Una historia de la imagen encuentra en los medios y en las técnicas de la imagen su forma temporal más plausible. Y sin embargo, ninguna antropología caería en el equívoco de pretender investigar las imágenes únicamente en la historia de su producción. Precisamente, el análisis de los medios es idóneo para desarrollar un concepto de imagen que no se pierda en contextos técnicos. Todas las imágenes conllevan una forma temporal, pero también acarrean en sí mismas interrogantes intemporales, para los cuales los seres humanos han concebido imágenes desde siempre. (pp. 69-70) 
Esto quiere decir que la materialidad de la imagen no se agota en lo técnico sino en la acción humana, que es necesariamente social. Aquí es donde entra Stuart Hall a complementar este llamado de Belting, ya que reconoce el carácter interactivo de lo que llama "significado cultural" y que aquí asumimos en términos generales como un sistema de representación: después de todo, los significados culturales no están solo "en la cabeza. Ellos organizan y regulan las prácticas sociales, influencian nuestra conducta y en consecuencia tienen efectores reales, prácticos" (Hall, 2003, p. 3). Y continúa:

El énfasis en prácticas culturales es importante. Estas participan en una cultura que otorga significados a personas, objetos y eventos. Las cosas "en sí mismas" raramente tienden a tener un singular, fijo e inmutable significado. Incluso algo tan obvio como una piedra puede ser una piedra, una marca de lindero o una pieza de alguna escultura, dependiendo de "qué significa"-esto es, dentro de un cierto contexto de uso, dentro de lo que los filósofos llaman diferentes "juegos de lenguaje" (...) Es en nuestro uso de las cosas, y de lo que decimos, pensamos y sentimos acerca de ellas - como las representamos como les otorgamos un significado. En parte, otorgamos significado a los objetos, a las personas y a los eventos por medio de marcos de interpretación. En parte, le damos significados a las cosas por medio del uso que le damos o cómo los integramos a nuestras prácticas cotidianas. (...) En parte, nosotros significamos a las cosas dependiendo de cómo las representemos-las palabras que usamos para referirnos a ellas, las historias que contamos sobre ellas, las imágenes que producimos acerca de ellas, las emociones que asociamos con ellas, las formas en las que las clasificamos y conceptualizamos, los valores que ponemos en ellas. (p. 3$)^{1}$

Ese énfasis interactivo de la comunicación humana es lo que permite resaltar el carácter material, medial, que tanto humanos como no humanos compartimos para darle sentido al mundo. Un sentido que es socialmente construido, pero no exclusivamente, ya que está condicionado por condiciones objetivas e intersubjetivas. Esto quiere decir que el ser humano adquiere su capacidad de conocer y apropiarse del mundo por medio de representaciones, las cuales deben ser entendidas como procesos intersubjetivos en los cuales intervienen aspectos tanto cognitivos como sociales y físicos que posibilitan la interacción comunicativa. Nunca percibimos la realidad en sí sino por medio de representaciones. Entonces, si entendemos a las representaciones como procesos 
constantes de apropiación y regulación de las interacciones humanas entre seres humanos y el mundo, debemos dejar de concebirlas como entidades discretas o productos sociales.

Son las imágenes, en tanto medios, las que sí deben ser entendidas como unidades discretas, las cuales son el resultado de los diferentes procesos de representación y que adquieren su concreción en una diversidad soportes, incluidas las llamadas imágenes mentales. A través de las imágenes es posible avizorar sistemas de representación, los cuales están en permanente transformación y no necesariamente existe una continuidad entre ellos. Esta es, a mi modo de ver, la premisa que sustenta el método genealógico que propone Foucault (i.e. 1968, 1993), ya que considera que las diferentes imágenes (especialmente verbales) deben ser consideradas como restos arqueológicos de una episteme (como sistema de representación) extinta, la cual es dinámica y debe ser leída entre líneas a través de las imágenes que ha producido.

Sin embargo, más allá de la propuesta metodológica para una historia de las ideas, lo que se busca aquí es mostrar cómo toda imagen, independientemente del sistema de representación del cual surge, así como adquiere nuevas significaciones en sistemas de representación que la reinterpretan, también aporta modos de significar a esos sistemas de representación y, en esa medida, se puede decir que contienen un mínimo de significado intrínseco (discernible más allá del contexto de producción o recepción).

Tanto lo que consideramos objetos como sujetos, son imágenes, es decir, medios a través de los cuales se decantan sistemas de significación y en los cuales estos sistemas se reproducen y transforman. No sólo los sujetos sino también lo que consideramos objetos, como lo afirman Lévi-Strauss (1987) y Butler (2002), son lugares de tránsito de sistemas de representación. Esto les da a estos autores la posibilidad de decir que no son necesariamente los sujetos, los ego, los que se manifiestan en la construcción de representaciones y discursos, sino que son simplemente medios a través de los cuales diferentes sistemas de representación se cruzan y se manifiestan. Tanto Butler como Lévi-Strauss concuerdan en que los sujetos son intersubjetivamente creados a través de sistemas de representación. Y en esta medida, los mecanismos de significación e interpretación moldean (masajean, diría McLuhan) a los sujetos, haciéndolos quienes son, por medio de estructuras que los anteceden y los condicionan, y no solo por medio del lenguaje articulado (como a veces parecen reducir estos autores a la comunicación humana). 
Nadie hay más contundente para expresar esto en un caso de exclusión que Judith Butler (2002) al hablar de lo queer:

La formación de un sujeto exige una identificación con el fantasma normativo del "sexo" y esta identificación se da a través de un repudio que produce un campo de abyección, un repudio sin el cual el sujeto no puede emerger. Éste es un repudio que crea la valencia de la "abyección" y su condición de espectro amenazador para el sujeto. Por otra parte, la materialización de un sexo dado será esencial para la regulación de las prácticas identificatorias que procurarán persistentemente que el sujeto rechace la identificación con la abyección del sexo. Y sin embargo, esa abyección rechazada amenazará con exponer las presunciones propias del sujeto sexuado, basadas como el sujeto mismo en un repudio cuyas consecuencias él no puede controlar plenamente. La tarea consistirá en considerar que esta amenaza y este rechazo no son una oposición permanente a las normas sociales condenada al pathos del eterno fracaso, sino más bien un recurso crítico en la lucha por rearticular los términos mismos de la legitimidad simbólica y la inteligibilidad. (pp. 20-21)

Si bien es cierto que los sujetos son lugares de enunciación, lo que olvida Lévi-Strauss y le recuerda Butler es que son lugares de enunciación muy específicos, con historicidades particulares que en gran medida condicionan (pero también seleccionan, distorsionan y hasta resisten o combaten) los sistemas de representación que en ellos se entrecruzan, permitiendo su modificación, resignificación o malinterpretación, en lo cual actúa también el azar. Y creo que esto es posible decirlo también acerca de los objetos en general, aunque de un modo más matizado.

En este punto también se queda corto este breve escrito, ya que hay un desarrollo importante en este sentido en las publicaciones académicas de universidades colombianas como la Universidad Central con la Revista Nómadas y la Universidad del Valle con la Revista Nexus; en las cuales es posible hallar análisis situados que muestran cómo entornos mediales como la televisión, la radio, la prensa y las artes. Está a la espera un análisis detallado de cómo en Colombia y Latinoamérica se ha generado un corpus de investigaciones con este corte y qué se ha logrado en los aproximadamente 25 años de este desarrollo. 


\section{Cosas, significados, ambigüedades y vacíos}

Las imágenes son las piezas, como bien lo acepta el estructuralismo, con las que se arman los sistemas de representación, los cuales a su vez no son solo una colección de imágenes. Las imágenes significan, cargan parte de su significado, pero no en una dimensión diferente a la de los mismos medios que las soportan sino en su materialidad. Las demás partes de la significación-representación se dan gracias a las diferencias entre contextos y a la intencionalidad de la lectura de la imaginería (sin contar con las condiciones azarosas que puedan presentarse en los diferentes momentos interpretativos de la vida cotidiana o el trabajo intelectual).

"En una semiología así concebida, la cuestión fundamental no es ya ‘¿qué significan los símbolos' sino ‘¿cómo significan?” Este parafraseo saussureano de Dan Sperber (1988, p. 77) parece estar en consonancia con lo dicho anteriormente, ya que reconoce la ligazón entre significante y significado. Esto, a pesar de tratar siempre de diferenciar "lo simbólico" de los signos lingüísticos, no pudo dejar al lenguaje articulado de lado en su análisis. Algo que también reconoce tanto para los unos como para los otros es su incompletitud: ya sea por lo críptico de lo que él llama lo simbólico (cayendo a mi parecer en lo que Belting señala como la metafísica de la tradición semiótica), ya sea por su posibilidad de acoplarse con otros elementos o piezas del sistema (como en un idioma, pero que supera la exploración lingüística estructuralista). Sperber, al tratar de introducir perspectivas cognitivistas, individualiza y mecaniza mucho a la forma en la cual significamos y representamos, por lo cual trataré de resaltar la buena síntesis que si hace de Saussure (y en otros momentos, de Freud).

Las palabras son y a la vez evocan imágenes, de un modo sinestésico casi siempre. El mismo Saussure reconocía que los morfemas (unidades mínimas con significado) e incluso los fonemas (unidades mínimas funcionales) eran imágenes dobles: una mental y otra sonora. Lo que permite la significación y la representación es la medialidad (sonora, visual, táctil... sinestésica en realidad) y su encuentro con los sistemas y marcos de imágenes mentales individuales, pero creadas en la interacción social con humanos y no humanos. Y esa interacción, a su vez, es generada por las imágenes que produce, olvidando algunas en el proceso, resignificando otras, de un modo dinámico e imperfecto de retroalimentación, muerte y transformación. Porque los sistemas de representación son parte de la vida y no son ajenos a sus leyes. 
Voy a tratar de demostrar esto, que los sistemas de representación no solo condicionan la forma de generar a las imágenes, sino que las imágenes en sí mismas tienen un mínimo significado inmanente, por medio de un par de ejemplos (ver Figura 1 y Figura 2).

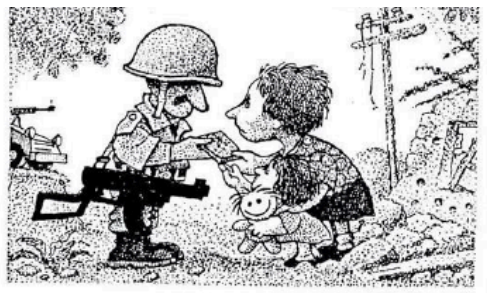

BOGROVO:UN SOLDADO DEL EJÉRCITO QUE APOYA ALDEMOCRÁTICO PRESIDENTE MAZEVICH REGALA CHOCOLATE A UNA MADRE Y SU HIJITA ENTRE LAS

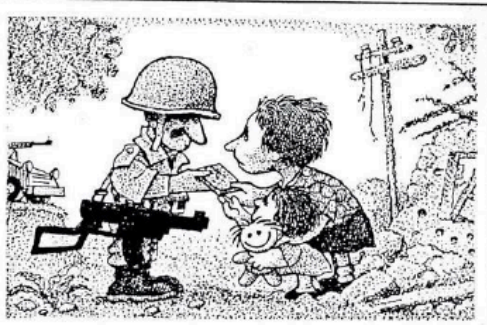

MAHÍLI:PARA CELEBRAR ELDÍA DEL EJÉRCITO LASMLJERES DE ESTE PEQUENO PAIS SIGUEN IA ANTIGUATRADICION DE OBSEQUIAR A CADA SOLDADO TABLETAS DE KAOE UN TIPICO DULCE ELABORADO CON SEMILLAS DE PUA'J.

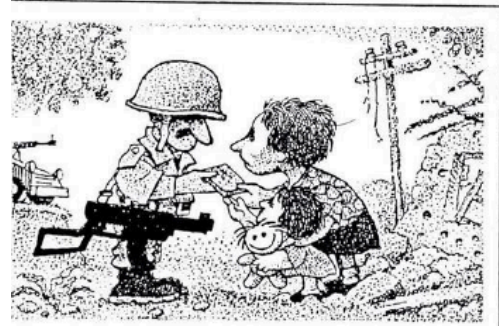

KÁFARA:UNA DEQUEÑA KAFARITA ENTREGAAUN INTEGRANTE DE LA MILICIA VENGADORES PORLA PAZ UN POEMA DE AGRADEC IMIENTO POR HABER DADOMUERTE A LOS NINNOS MALUFITAS QUE HABIAN ROBADOSU MUNNECA.

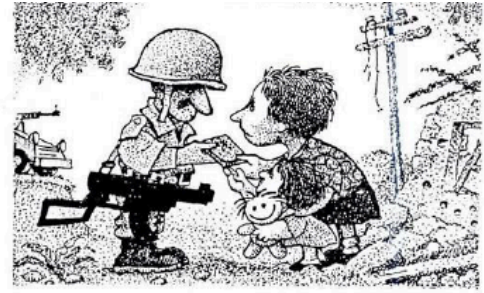

SAN JUANDE TALPINGO:UN AGENTE DEL CUERPO ANTINARCOTICOS CONTROLA LOS DOCUMENTOS DE UNA CAMPESINA. MUCHASDE ELLAS UTILIZANA SUS HIJOS PARA PASAR DROGA OCULTA EN SUS JUGUETES.

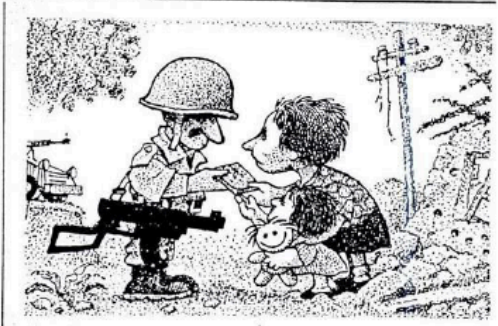

GINEBRA:UN INFORMEDEL UNICEF REVELA QUE CRECE EN TODO EL MUNDO EL NÜMERO DE NIÑOS VICTIMAS DE ABUSO SEXUAL.EN LA FOTO, UNA MADRE OFRECESL PEQUENAA HITA AUN IGNOTO SOLDADO A CAMBIO DE UN POCODE CHOCOLATE

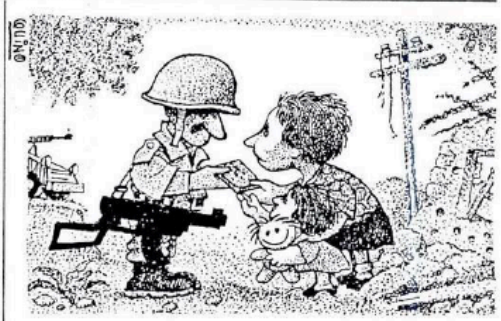

BOGROVO:UN GUERRILLERO DEL. FRENTE PATRIÓTICO REGALA CHOCOLATE A UNA MADRE Y SU HIJITA ENTRE LAS RUINAS DE SU CASA DESTRUIDA POR EL EUERCITO QUEAPOYA AL SANGLINARIO PTE.MAZEVICH.

Figura 1. La ductilidad de las imágenes, incluidas las palabras.

Nota: tomando nota de las diferencias que hay entre la primera y la última descripción de "pie de foto", vemos que Quino usa la misma imagen lingüística ("regala chocolate a una madre y su hijita entre las ruinas de su casa destruida por") para dar dos sentidos en disputa entre la primera y la última viñeta, lo que nos muestra que no solamente las imágenes visuales son polisémicas y abiertas sino todo tipo de práctica significante (usando las palabras de Hall, 2002).

Fuente: Quino (2005). 


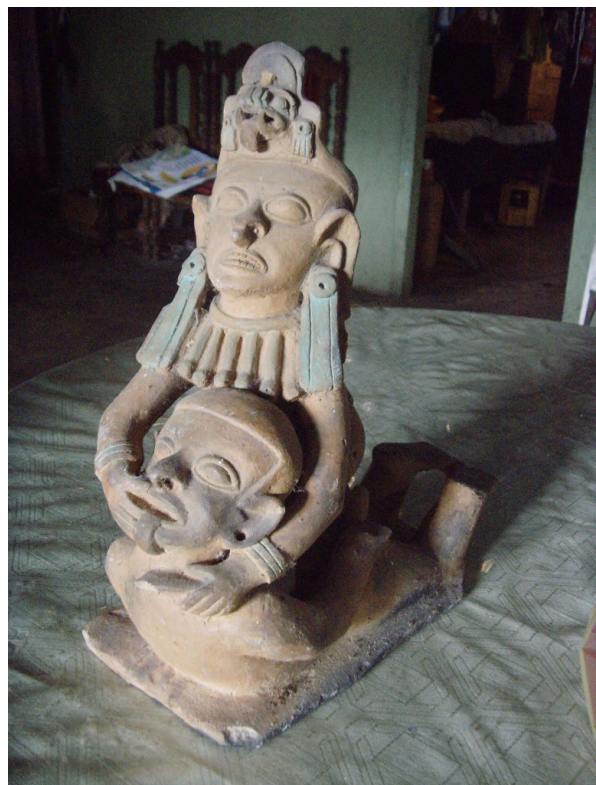

Figura 2. Artesanía de La Tolita Pampa de Oro (Esmeraldas) de una pieza arqueológica hallada en la misma isla. Fuente: fotografía tomada por Miguel Rivera (2009).

Observemos en primera medida una caricatura de Quino (ver Figura 1). En esta caricatura hay una sola imagen y al menos seis formas de representación en disputa que van a hacer que el sentido de la imagen (que es de una acción) se transforme radicalmente en términos de la dirección del mensaje. Sin embargo, perdura una mínima dosis de agencia (en términos de Latour, 2005) que hace posible que estos diferentes sistemas de relación entren a luchar por el sentido de tales imágenes.

En consecuencia, cuando los sociólogos son acusados de tratar a los actores como marionetas, deben recibirlo como un elogio, siempre que multipliquen los hilos y acepten que haya sorpresas en la actuación, el manejo y la manipulación. "Tratar a la gente como marionetas" es una maldición cuando esta proliferación de mediadores es transformada en una agencia -lo social- cuyo efecto es transportado simplemente, sin deformación a través de una cadena de intermediarios. (p. 92)

Y esos intermediarios son las imágenes con toda su medialildad. Las imágenes son actantes en términos de Latour, y reconocer que su materialidad, su medialidad, contiene un mínimo de significado es reconocer su agencia. Además, este autor siempre está hablando de la agencia en términos de acción, de ejecución. 
Si tomamos el dibujo de Quino en sí, independientemente de cada "pie de foto", podemos extraer, como mínimo, la siguiente información sin necesidad de entrar en los detalles de la dirección del mensaje. Podemos ver, por ejemplo, que la acción que allí se pone en escena se encuentra en un contexto bélico y que existe una interacción directa entre ciertas partes de las tropas de un bando y la sociedad civil. Si bien las ruinas urbanas, el casco, las armas, la muñeca son medios generados en sistemas de representación muy concretos y contemporáneos, la escena general y la severidad de los rostros nos traen a la mente, como mínimo, la imagen de una guerra.

Ahora bien, probablemente la idea de Quino no haya sido tanto la de mostrar la unicidad de cierta significación mínima de la imagen sino por el contrario la diversidad de direcciones que puede tomar la interpretación de ésta. Pero, haciendo la lectura, al contrario, espero encontrar un camino para responder la pregunta que guía esta breve disquisición, que podría reformularse como ¿cómo interpretar a las imágenes?

En el proceso de creación de imágenes, lo que comúnmente se ha llamado representación, claro que existe un proceso de traducción, la cual siempre implicará, como se anotó, tanto una pérdida como una ganancia. Lo que se pierde en el proceso de concreción de imágenes es la generalidad y la dinamicidad de los sistemas de representación que, como bien lo arguye Lévi-Strauss (1987), tienden a ser holísticos. Pero a diferencia de Lévi-Strauss y más cercanos a Foucault (1968), estos sistemas de representación son más bien dinámicos y en permanente reproducción y transformación. Esto quiere decir que, al crear una imagen que tienda a representar a otra, los sistemas de representación se concentran y se especifican en la pragmática que impone el contexto, tanto de creación como de recepción y de circulación (lo cual hace que el carácter holístico y dinámico de los sistemas de representación se vean decantados en medios específicos y estáticos, lo cual contribuye con la misma dinamicidad de estos sistemas).

Pero hay más. Como es posible notar en el ejemplo de Quino, las imágenes mismas poseen un mínimo de significación intrínseca que hace posible la traductibilidad del mensaje y el significado "completo" de ésta a diferentes y hasta opuestos sistemas de representación. Esto quiere decir que la misma imagen posee cierta capacidad para permitir esta traducción entre sistemas de representación, lo cual me lleva a un par de preguntas más: ¿esto quiere decir que no toda imagen estará dispuesta a ser significada por cualquier sistema de representación o, al contrario, todo sistema de representación está en la facultad para dotar de sentido 
a cualquier imagen? Y, dependiendo de la respuesta, ¿será posible que encontrar los significados mínimos intrínsecos de imágenes, a las cuales sólo podemos acceder por su materialidad y las cuales son los únicos insumos para conocer sistemas de representación extintos (como los de los objetos arqueológicos de la cultura arqueológica Tumaco-La Tolita)?

Espero dejar en claro que la respuesta a la primera de estas dos preguntas es que toda imagen puede ser interpretada en términos de cualquier sistema de representación, pero esta interpretación estará en gran medida condicionada por un mínimo de características intrínsecas de esa imagen. Además, la interpretación que se dé de ésta en un sistema de representaciones dado dependerá en gran medida del papel que cumplan las representaciones que se activen por medio de esa imagen en concreto. Esto me lleva a la segunda pregunta, la cual, creo que debe ser respondida con un tímido sí. Y lo digo porque, si bien en una imagen, como la que se muestra en la Figura 2, es posible ver que hay una escena de sacrificio o muerte de un humano por parte de otro, esto no nos dice nada acerca de la dirección de tal sacrificio ni del sentido de la muerte en sí misma. Pero trataré de responder estas preguntas de un modo más concreto, a continuación.

\section{Medialidad, contexto y exégesis}

Todo acto de representación, es decir, de construcción y reproducción de imágenes, implica una transformación del sentido (incluso dentro de un mismo sistema de representación) de la imagen en cuestión, lo cual no necesariamente deba ser visto como una pérdida sino como una resignificación en donde lo que se pierde se gana en términos de contextualización. Esto espero haberlo dejado relativamente claro, lo que no queda tan claro es cómo se da ese proceso de traducción y cuáles son los límites de una interpretación (como la que pretenden hacer los arqueólogos posprocesualistas).

Es difícil especificar esto debido a que todo acto de interpretación está ligado a un contexto y, como se especifica en la nota de la Figura 1, toda imagen (entendida desde la semiología general que propone, aunque no profundiza, Saussure) es susceptible de transformar su sentido dependiendo de las relaciones que establezca con otras imágenes. Y, en vez de buscar en la pretendida posibilidad abierta de las imágenes visuales como una exclusividad de estas, es posible notar cómo las imágenes sonoras y escritas (como las palabras que hacen parte de las viñetas de Quino) son igualmente polisémicas y abiertas en su interpretación. Por lo cual, es posible decir que, a pesar de la arbitrariedad que existe entre las imágenes 
verbales que usamos para designar las cosas (así como la arbitrariedad/ convencionalidad que existe en la forma de significar, por ejemplo, la "foto" que nos muestra Quino en sus seis viñetas), cada imagen posee, según mi argumento, una dosis mínima de significado intrínseco.

Existen, no obstante, una serie de limitaciones significativas en términos de identificar el significado mínimo intrínseco de una imagen cualquiera. Espero, por medio de la identificación de estas limitaciones o condicionamientos, contribuir con la construcción de una base para la creación de una metodología de interpretación y crítica visual.

Creo que estas limitaciones o condiciones tienen que ver, en gran medida, con varios aspectos, entre ellos, los más relevantes y que no se han mencionado son: la historicidad compartida o convergente (o legibilidad) y la intención de lectura. Esto es lo que marca la distancia entre las imágenes analizadas en las figuras 1 y 2 para el caso de nuestro contexto de recepción de tales imágenes, y por medio de ellas trataré de mostrar esas limitaciones.

En este punto, debido a las limitaciones de espacio y tiempo, sólo quisiera aclarar que esta propuesta de ver lo que llamo una historicidad compartida lo tomo especialmente de la propuesta de Appadurai (2001) en términos de considerar que la producción de representaciones (incluida la etnografía, el periodismo y las artes, así como cualquier obra teórica y este mismo texto) depende en gran medida de una multiplicidad de flujos que convergen y divergen, que se complementan, niegan, chocan y fusionan dependiendo de las trayectorias temporales y espaciales en las que se han manifestado como imágenes, permitiendo ver "el modo en que la historia y la genealogía se afectan mutuamente, y cómo los hechos globales adquieren una forma local" (p. 21), lo cual no solo aplicaría al análisis de la globalización contemporánea sino a cualquier sistema de representación en cualquier época. Esto implica que debemos reconocer los hiatos, las distancias y los vacíos que se generan por las condiciones particulares de los contextos históricos, políticos, económicos y representacionales en los que se producen las imágenes.

En este sentido, la caricatura de Quino nos es más cercana, ya que de cierto modo hemos compartido con el autor, al menos en mi caso, una misma lengua, un contexto latinoamericano y algunos acontecimientos globales, así como el valor de la prensa para la democracia y la vida urbana. En esta medida, compartimos muchos elementos históricos que hacen más legible al caricaturista a los miembros de mi generación en la región que habito. Cosa muy diferente con respecto a la imagen del decapitador 
de La Tolita, ya que nuestra historicidad diverge desde el mismo contexto lingüístico y tecnológico, así como religioso y político; a pesar de estar más cercanos geográficamente, los casi dos mil años que nos separan son en sí mismo un hiato insalvable. Hacer una evaluación en este sentido de convergencia o divergencia de historicidad o legibilidad es indispensable para iniciar cualquier análisis sobre las imágenes a estudiar.

A su vez, complemento esta perspectiva con la propuesta de Moxey (2005), tomando el concepto de "epistemología de la mirada" (la cual se concentra en la intencionalidad de esta), el cual involucra no sólo el contexto específico de interpretación y traducción sino a la vez las condiciones propias del hecho de ver e interpretar para conocer cómo la misma imagen opera en diferentes sistemas de representación y cómo la subjetividad condiciona tanto los contextos como la interpretación misma.

Siguiendo el argumento del choque de miradas y la posibilidad de ser contestadas y contradichas, Moxey (2005) asegura que: "No todos los miembros de una cultura apoyan con el mismo entusiasmo los valores reinantes, ni tampoco coinciden las apreciaciones personales y particulares de los objetos" (p. 36), a lo cual le agregaría que no todos prestamos atención a lo mismo y con diferentes intensidades de observación.

Esto es particularmente relevante para el análisis de las imágenes y es no solo evaluar las distancias históricas que nos separan o unen a las imágenes que analizamos, sino aumentar la reflexividad a la que aluden autores como Murphy y Banks (1997) o Elisenda Ardevol (1994) como parte importante de la amplia "antropología visual". Esta reflexividad no es el pretendido hedonismo narcisista al que lo reducen los objetivistas, sino una necesidad epistemológica para reconocer la mirada propia. ¿Cómo pretendo conocer las formas de percibir si no conozco mi propia forma de percibir? Y muchas veces se nos olvida que la intensidad de nuestra mirada academizada es mayor en muchos sentidos y trata de poner énfasis conscientes donde lo subconsciente es lo que impera.

Son intensidades, direcciones y utilidades diferentes las que nos distancian a mí de Washo, un amigo artesano, empresario y pescador de La Tolita que realizó la réplica de la Figura 2. Las condiciones y finalidades de la lectura que hace Washo se distancian de la mía varios sentidos: él aprendió a hacer esculturas cerámicas imitando las que abundan en la isla, le llaman la atención sus acabados y temas (de los más diversos y bien trabajados para esta época en la zona) y, en cierta medida, se siente intrigado por esta escena. Muy probablemente yo también me sienta intrigado y sea llamada mi atención por las mismas cosas, pero la 
forma en la cual yo las apropio a mi mundo (por ejemplo, la fotografía y la investigación etnográfica) es bien diferente a la de Washo (con la escultura y la reflexión onírica). En esa confrontación de nuestros intereses y miradas sobre el mismo objeto, hacen que choquen sobre aquella imagen, haciendo más ricos sus significados para nosotros y nuestros sistemas de representación, convirtiéndose en un referente más para compartir en la convergencia de las historicidades entre Washo y yo. Todo ello a pesar de la inmovilidad de la pieza, fiel reflejo de un artefacto excavado en la isla y vendido probablemente en Tumaco o Esmeraldas. Algo similar hubiera pasado si hubiera leído con Washo la caricatura de Quino de la Figura 1.

Con esta descripción quiero señalar que hay toda una carga que nosotros como investigadores de la imagen traemos a nuestras lecturas. Efectivamente habernos alimentado teóricamente nos posibilita la creación y organización de nuestras preguntas, pero también en varias investigaciones (no solo acerca de las imágenes) parece que nada se aprendiera empíricamente, sino que todo debe ser encasillado previamente, lo cual cierra la posibilidad de aprender de lo que percibimos. Saber identificar los momentos en los cuales, como investigadores de la imagen, estamos reduciendo y cerrando las potencialidades interpretativas se hace imperativo. Y esto no es un requisito deseable por ser aparentemente políticamente correcto, sino porque estos objetos, las imágenes, son interactivos.

Esto se vincula con el otro elemento epistemológicamente relevante que señalan Ardevol con Morphy y Banks: la colaboración. Y es una colaboración en, al menos, tres niveles: entre las disciplinas, al interior de los equipos de trabajo y con los protagonistas de nuestras investigaciones sociales. Colaborar implica abrirse a la cointerpretación, a la coelaboración y a la crítica cultural colectiva. Y no solo por principios incluyentes y equitativos, sino porque en la construcción colectiva de los análisis es necesaria para abarcar la mayor cantidad de miradas, ya que estas están cargadas con historicidades muy específicas.

El choque de las miradas, por las cargas subjetivas e históricas particulares que implican, nos obliga a emprender investigaciones sobre las imágenes donde estas entran en pugna, se complementan o anulan mutuamente, por lo cual debemos saber ubicar nuestra propia mirada, reconocer la forma en la cual concentramos nuestras energías en ellas, y silenciamos o privilegiamos ciertas formas en relación con otras. Por ello el llamado de Hall de ver a la representación como proceso implica ver cómo estas entidades discretas que llamamos imágenes sólo se completan (siguiendo a Sperber) en la acción, en la práctica social, en la interacción humana. 
Entonces tenemos tres aspectos interrelacionados: 1. Las características intrínsecas de las imágenes, las cuales creo que se refieren a su materialidad y soporte y, como lo acepta Belting (2002), es en el medio en donde debemos buscar parte del ejercicio de traducción en términos de transmisión de cierto significado (sea esta transmisión efectiva y contextual o no); siguiendo con Belting, pero complementado con Appadurai (2001) y Hall (2001), vemos que es necesaria una perspectiva antropológica que dé cuenta de 2 . Los contextos históricos así como la dinamicidad de estos en términos de prácticas significantes para conocer la forma en la cual se ha cargado y descargado de significados estas imágenes/medios y notar la ductilidad (no ilimitada debido a las características intrínsecas del medio) en la que se expresa su significación; esto, tomando en cuenta a la vez un aspecto más perceptual: 3 . La intencionalidad de la "mirada" que posibilita la lectura misma de cada imagen/medio, permitiendo no solamente una necesaria reflexividad sino la apertura colaborativa con otras reflexiones particulares. Esto implica dejar de ver a las imágenes en sí y comenzarlas a ver en su interacción. Implica dejar de preguntarnos a secas ¿qué significa una imagen?, y empezar a preguntarnos ¿cómo significa una imagen en un contexto social específico, qué historicidades se encuentran en ese contexto y cómo interactúan en la lectura (apropiación y valoración) de determina(s) imagen(es)?

Si tomamos en cuenta estos tres aspectos es posible comprender el abismo que separa las imágenes de las figuras 1 y 2 , a la vez que es posible notar la necesidad de ser más arriesgados en términos de interpretación en unos casos que en otros. En el caso que nos presenta Quino podemos identificar más fácilmente los diferentes elementos expuestos en tal imagen, como el fusil, la muñeca, el tanque de guerra, porque hacen parte de nuestro mundo contemporáneo, porque hemos leído periódicos que nos hablan sobre estos objetos y sobre la guerra, porque hemos estado en contacto con fotografías que nos dicen mucho acerca de este tipo de época. Pero a la vez, porque como investigadores sociales, tenemos una obsesión por la lectura de todo: buscamos respuestas como vicio, sentimos la necesidad/necedad de interpretar todo. Por eso, no necesariamente por ser más o menos contemporáneos con el contexto de producción de tal imagen vamos a interpretar y conocer profundamente esa imagen, pero al menos sí tendremos más elementos en el mundo circundante para dar cuenta de los significados de las imágenes y reírnos amargamente con el chiste del genio argentino. Además, la forma en la cual se interpreta dicha imagen será diferente en un contexto más político que este, y variará en cuanto involucremos más sujetos y contextos en los que esta imagen haya sido consumida, reapropiada, circulada o censurada. 
Lastimosamente esto no pasa con la imagen de La Tolita. Si bien el exceso de interpretación es el mismo (no es sino asomarse a la basta bibliografía sobre análisis formales de piezas -casi en su totalidad huaqueadas- que hay en la arqueología de los Andes septentrionales), nunca vamos a tener la misma cantidad de información, de imágenes y de sistemas de representación con la que contamos para dar cuenta de los contextos de producción y circulación de la caricatura de Quino. Pero al menos contamos con ese objeto en sí, el cual nos está diciendo, como mínimo, que ese acto de degollamiento ha sido digno de ser representado por ellos, que eran grandes productores de alfarería y aspectos generales relacionados además con otras imágenes/medios. Mínimo, en este caso, nos habla de ciertas habilidades e intereses de sus creadores, aunque tal vez nunca sepamos los contenidos concretos de las intencionalidades que los movieron. Pero el arqueólogo que busca interpretar una figura como esta, no cuenta solamente con la materialidad de esta imagen. Al menos para el caso de La Tolita, existen algunas investigaciones importantes desde la última década del siglo pasado, su cerámica es relevante en las colecciones museográficas de Ecuador y Colombia, el entorno de manglares, los camellones y sistemas hidráulicos prehispánicos es cada vez mejor conocido y existe mucha evidencia ecofactual. La labor del arqueólogo no es interpretar la pieza cerámica en sí, sino en su contexto social reconstruido a partir de lo que llamamos "cultura material". Esto le da a estos otros investigadores de las imágenes elementos varios para explorar hipótesis de interpretación, evidenciando su propia mirada y reconociendo que hay vacíos que nunca serán llenados.

\section{Recapitulando}

Hay un límite para la interpretación, y este se marca en gran medida por medio de la convergencia y divergencia de las historicidades entre los diferentes elementos que componen el proceso de interpretación/significación. Como la historicidad de la caricatura de Quino nos es más cercana y compartida que la de la pieza de La Tolita, las posibilidades de interpretación son mayores en cuanto a la contextualización de su producción y el sentido que el creador le quiso dar.

Pero, en términos más generales, y como se dijo al comienzo de este ensayo, todo es susceptible de ser interpretado; lo que se quiere hacer énfasis acá es que la posibilidad de conocer las intencionalidades involucradas en la producción de determinada imagen se aleja en la medida en que las historicidades que constituyen los contextos de producción y de recepción dejan de cruzarse. Pero, al existir referentes (como en el caso 
de ambos ejemplos, del cuerpo humano ${ }^{2}$ ) que a pesar de sus múltiples significaciones son comunes a la especie humana, se abre la inmensa posibilidad de hacer que cada imagen encuentre sentido en cada cruce de sistemas de significación en el que se enclave.

Es decir, a pesar de la diversidad de sistemas de representación, de la complejidad que impone la historicidad de estos, de la falta de un significado situado para cada imagen y de la inmensidad de intencionalidades subjetivas del "ver"; es posible notar que es en la misma imagen, como medio, que radica la posibilidad de traducción/interpretación de esa imagen en cualquier sistema de significación. Pero a la vez, que esa traducción/interpretación será más compatible con los sistemas de significación presentes en el contexto de producción, en la medida en que ese contexto de producción sea mejor conocido y sea más cercano al contexto de recepción (a lo cual se le debe sumar la disposición subjetiva de leer en si tal imagen/medio).

Abrir la posibilidad de una lectura como medio de las imágenes, recalcando su materialidad, interactividad e intersubjetividad se hace necesario para superar la metafísica del análisis de los imaginarios. Lo mismo pasa con el reconocimiento de la historicidad de las miradas, la importancia de la reflexividad y la colaboración en la interpretación de estos imaginarios sociales más allá de una sola disciplina y de la tradición académica en general que termina siendo escolástica y hacer ver estáticos a los sistemas de representación.

\section{Referencias bibliográficas}

Appadurai, A. (2001). La Modernidad Desbordada. Editorial Trilce S.A.

Ardévol, E. (1994). La mirada antropológica o la antropología de la mirada: de la representación audiovisual de las culturas a la investigación etnográfica con una cámara de video (Tesis Doctoral). UAB, Barcelona, España.

Belting, H. (2002). Antropología de la Imagen. Katz Editores.

Butler, J. (2002). Cuerpos que importan: Sobre los límites materiales y discursivos del 'sexo'. Paidós.

Foucault, M. (1993). Historia de la Sexualidad I: La Voluntad de Saber. Siglo XXI Editores.

Foucault, M. (1968). Las Palabras y las Cosas. Siglo XXI Editores.

\footnotetext{
Pienso, por ejemplo, en cómo sería la reacción y la traducción que haría un grupo de personas que nunca hayan pisado una ciudad, como los taromenani o los nukak makú, de alguna película clásica de Chaplin. Especulo que, si bien se sorprenderán por el contexto urbano y no sepan qué son esas máquinas ni para qué sirven, creo que podrían comprender en gran medida los estados de ánimo de Charlot, pero de que se rían o no depende de manera en la cual son significados esos estados de ánimo.
} 
Hall, S. (2001). Introduction. En S. Hall (ed.), Representation: Cultural Representations and Signifying Practices (pp. 1-11). Sage Publications.

Latour, B. (2005). Reensamblar lo social. Una introducción a la teoría del actor-red. Manantial. Lévi-Strauss, C. (1987). Mito y Significado. Alianza.

Mauss, M. (1979). Técnicas y movimientos corporales. En Presses Universitaires de France (ed.), Antropología y Sociología (pp. 337-356). Editorial Tecnos.

Moxey, K. (2005). Estética de la cultura visual en el momento de la globalización. En J. Brea (ed.), Estudios Visuales (pp. 27-37). Akal.

Murphy, H. y Banks, M. (1997). Rethinking Visual Anthropology. Yale University Press.

Quino. (2005). Esto no es todo. Ediciones de la Flor.

Saussure, F. (1980). Curso de lingüística general. Losada.

Sperber, D. (1988). El simbolismo en general. Anthropos. 